\title{
Editorials
}

\section{HIV transmission in serodiscordant heterosexual couples}

BMJ 2010; 340 doi: http://dx.doi.org/10.1136/bmj.c2449 (Published 26 May 2010) Cite this as: BMJ 2010;340:c2449

- Article

- Related content

- Metrics

- Responses

- Peer review

Marie-Claude Boily, senior lecturer in infectious disease ecology 1, Anne Buvé, professor2, Rebecca F Baggaley, research fellow 1

\section{Author affiliations}

mc.boily@imperial.ac.uk

Risk is not zero but is low if the infected partner takes antiretrovirals

Antiretroviral treatment inhibits HIV viral replication and reduces plasma viral load. Low plasma viral load is associated with a lower probability of HIV transmission, which opens the possibility of treatment to reduce HIV transmission.12 The feasibility, potential effectiveness, and risks of such treatment are unclear, and a key uncertainty is the extent to which successful antiretroviral treatment reduces HIV infectivity. In the linked observational study (doi:10.1136/bmj.c2205), Del Romero and colleagues estimate the risk of heterosexual transmission of HIV-1 from infected people taking combined antiretroviral treatment.3

Only randomised controlled trials comparing transmission in HIV serodiscordant couples, where the infected (index) partner receives or does not receive antiretroviral drugs, can accurately estimate the effect of such treatment on infectivity. The HPTN-052 trial is the only ongoing trial of this type. In this trial, partners infected with HIV are assigned to immediate antiretroviral treatment or deferred treatment when their CD4 count drops below 250 cells/ $\mu$ l. This trial will hopefully provide a good estimate of the effect of antiretroviral treatment in patients with more than $250 \mathrm{CD} 4 \mathrm{cells} / \mu \mathrm{l}$, but it will obviously not obtain an estimate in patients with fewer than 250 CD4 cells/ $\mu$ l.

Evidence that antiretroviral treatment reduces sexual transmission of HIV comes from observational studies of serodiscordant couples and ecological studies,2 45 but transmission from patients on antiretroviral treatment has also been documented.6 Del Romero and colleagues' study is a welcome addition to the observational studies that estimate infectivity in serodiscordant couples. In partners of patients with HIV not receiving treatment, the incidence of HIV was 0.6 per 100 couple years, whereas none of the partners of patients on antiretroviral treatment seroconverted (fig $1 \underline{\Downarrow}$ ). The authors also computed the probability of transmission per unprotected sex act (fig $2 \underline{\Downarrow}$ ). The infectivity estimates were low and imprecise, with no significant difference between treated and untreated patients (figs 1 and 2). The authors therefore conclude that transmission of HIV from successfully treated patients cannot be 
excluded, because it is biologically possible and because the data are consistent with one infection per 91 couple years (compared with one per 71 couple years in untreated couples). Moreover, because this is an observational study, the treated and non-treated groups are most probably not comparable. Patients receiving treatment are necessarily different because of their poorer clinical history. Some differences were also seen in risk behaviour and characteristics of the index partners at baseline and during followup, which may have increased transmission in couples with an untreated index partner.3

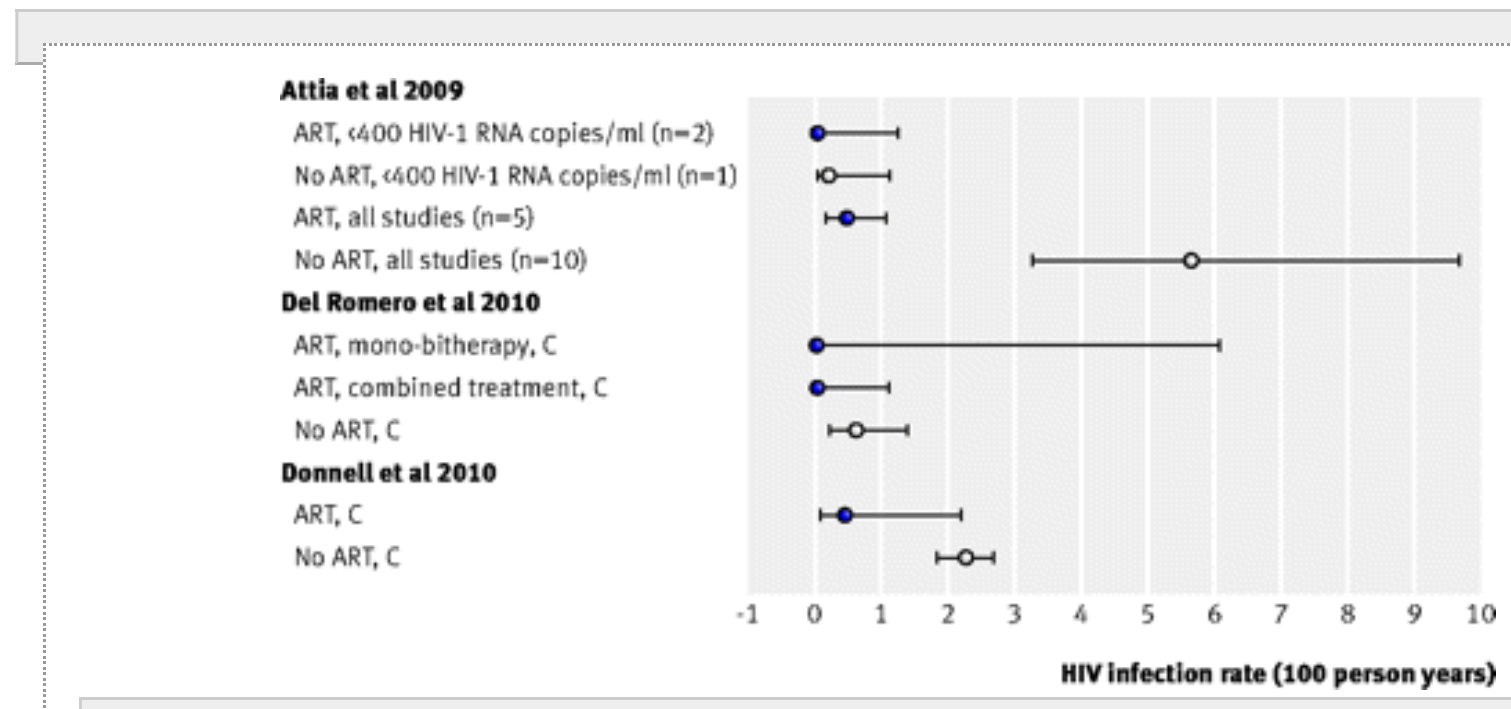

Fig 1 HIV infection rates in serodiscordant couples. Data are from two observational studies 37 and a meta-analysis. $4 \mathrm{n}=$ number of studies included in the pooled estimate; $\mathrm{C}=$ male and female combined

Download figure Open in new tab Download powerpoint

\section{Del Romero et al 2010}

ART, mono-bitherapy, C

ART, combined treatment, C

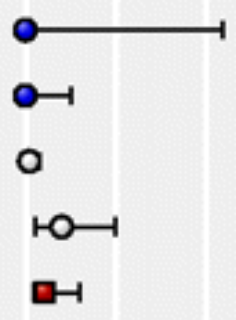

With condoms, C

o

No ART, C

10-1

All couples, $\mathrm{C}$

마

\section{Boily et al 2009}

$C$, high income countries ( $n=4)$

FM, high income countries $(n=3)$

MF, high income countries $(n=10)$

$F M$, low income countries $(n=5)$

$M F$, low income countries $(n=7)$

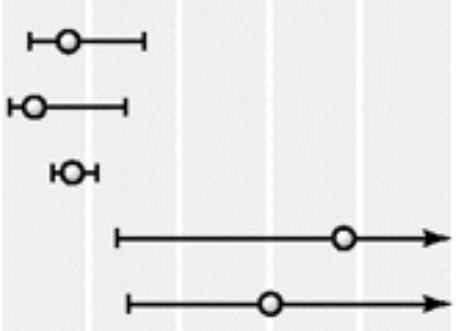

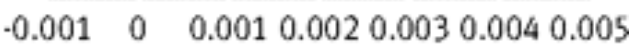

\section{Transmission risk per sex act}

Fig 2 Per sex act heterosexual transmission probability estimates with and without antiretroviral treatment (ART) 3 compared with pooled estimates before the ART era. $8 \mathrm{n}=$ number of studies 
Download figure

Open in new tab

Download powerpoint

How do the results of Del Romero's study compare with other studies? Apart from four studies from high income countries conducted before the era of antiretroviral treatment that also reported no seroconversion, the infectivity estimates in the non-treated group were generally lower in Del Romero's study than in previous studies.4 $89 \mathrm{~A}$ recent systematic review of observational studies in heterosexual serodiscordant couples found five studies reporting HIV infectivity estimates according to treatment. In two of these studies with information on viral load, no seroconversions were seen when treated index patients had viral loads of fewer than 400 copies $/ \mathrm{ml}$. One study from Uganda reported no seroconversions in partners of treated cases despite only $79 \%$ having achieved a viral load fewer than $400 \mathrm{copies} / \mathrm{ml}$ six months after the start of treatment. A more recent study (not in the systematic review4) in seven African countries observed one seroconversion in 256 person years of follow-up in partners of index cases. 7

Together, these seven studies of patients receiving antiretroviral treatment independently of viral load will help to provide a more precise overall estimate of the seroconversion rate.34 7 Although the probability of transmission during antiretroviral treatment seems to be greater than zero, these studies support the idea that treatment reduces infectivity, which could translate into benefits at the population level, as long as risk behaviour does not increase. To date, some studies, 5 but not all, 10 suggest a beneficial effect of antiretroviral treatment at the community level.

What effect do these data have on counselling serodiscordant couples? In 2008, the Swiss Federal AIDS Commission released a controversial statement to the effect that HIV infected people with undetectable concentrations of the virus ( $<40 \mathrm{copies} / \mathrm{ml}$ ) for at least six months, who adhered to a strict antiretroviral drug programme and had no other sexually transmitted infections, were not infectious to their regular heterosexual partners.11 The challenge for counsellors is to ensure that people understand the exact set of conditions and time period when it seems to be safe to have unprotected sex. Del Romero and colleagues are more cautious and continue to promote the use of condoms regardless of viral load; in their study condom use reduced HIV transmission by $93 \%$.

On the basis of current evidence, we conclude that although taking antiretroviral treatment reduces the risks of vaginal intercourse with an HIV positive partner, intercourse is not totally risk free. Despite their limitations, additional studies in discordant couples are needed to estimate the infection risk more precisely, especially for homosexual and heterosexual anal intercourse. 812 It is unclear how these results for heterosexual populations will translate to homosexuals.

\section{Notes}

Cite this as: BMJ 2010;340:c2449

\section{Footnotes}

\section{- Research, doi:10.1136/bmj.c2205}

- Competing interests: All authors have completed the Unified Competing Interest form at 


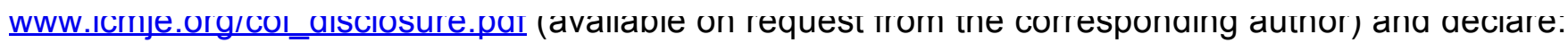
(1) No financial support for the submitted work from anyone other than their employer; (2) No financial relationships with commercial entities that might have an interest in the submitted work; (3) No spouses, partners, or children with relationships with commercial entities that might have an interest in the submitted work; (4) No non-financial interests that may be relevant to the submitted work.

- Provenance and peer review: Commissioned; not externally peer reviewed.

\section{References}

1. $\downarrow$ Quinn TC, Wawer MJ, Sewankambo N, Serwadda D, Li C, Wabwire-Mangen F, et al. Viral load and heterosexual transmission of human immunodeficiency virus type 1. N Engl J Med2000;342:921-9. CrossRef Medline Web of Science

2. $\downarrow$ Cohen MS, Gay C, Kashuba ADM, Blower S, Paxton L. Narrative review: antiretroviral therapy to prevent the sexual transmission of HIV-1. Ann Intern Med2007;146:591-601. CrossRef Medline Web of Science

3. $\downarrow$ Del Romero J, Castilla J, Hernando V, Rodríguez C, García S. Combined antiretroviral treatment and heterosexual transmission of HIV-1: cross sectional and prospective cohort study. BMJ2010;340:c2205. Abstract/FREE Full Text

4. $\downarrow$ Attia S, Egger M, Müller M, Zwahlen M, Low N. Sexual transmission of HIV according to viral load and antiretroviral therapy: systematic review and meta-analysis. AIDS2009;23:1397-404. CrossRef Medline Web of Science

5. $\downarrow$ Montaner J, Wood E, Kerr T, Yip B, Lima V, Shannon K, et al. Association of expanded HAART coverage with a decrease in new HIV diagnoses, particularly among injection drug users in British Columbia, Canada [abstract]. Seventeenth Conference on Retroviruses and Opportunistic Infections, San Francisco, 2010:88LB.

6. $\downarrow$ Sturmer M, Doerr HW, Berger A, Gute P. Is transmission of HIV-1 in non-viraemic serodiscordant couples possible? Antiviral Ther2008;13:641-2. Medline Web of Science

7. $\rfloor$ Donnell D, Kiarie J, Thomas K, Beaten J, Lingappa J, Cohen C, et al. ART and risk of heterosexual HIV-1 transmission in HIV-1 serodiscordant African couples: a multinational prospective study [abstract]. Seventeenth Conference on Retroviruses and Opportunistic Infections, San Francisco, 2010:136.

8. JBoily MC, Baggaley RF, Wang L, Masse B, White RG, Hayes RJ, et al. Heterosexual risk of HIV-1 infection per sexual act: systematic review and meta-analysis of observational studies. Lancet Infect Dis2009;9:118-29. CrossRef Medline Web of Science

9. $\downarrow$ Baggaley RF, White RG, Boily MC. Heterosexual HIV infectivity estimates from prospective discordant couples studies by gender and setting: a systematic review and meta-analysis [abstract]. Seventeenth International AIDS Conference, Mexico City. 2008:MOPE0321.

10. $\downarrow$ Bezemer D, de Wolf F, Boerlijst MC, van Sighem A, Hollingsworth TD, Prins M, et al. A resurgent HIV-1 epidemic among men who have sex with men in the era of potent antiretroviral therapy. AIDS2008;22:1071-7.

CrossRef Medline Web of Science

11. $\downarrow$ Vernazza P, Hirschel B, Bernasconi E, Flepp M. Les personnes séropositives ne souffrant d'aucune autre MST et suivant un traitement antirétroviral efficace ne transmettent pas le VIH par voie sexuelle. Bulletin des Médecins Suisses2008;89(5). www.saez.ch/html f/2008/2008-05.html.

12. $\lrcorner$ Baggaley RF, White RG, Boily MC. HIV transmission risk through anal intercourse: systematic review, metaanalysis and implications for HIV prevention. Int J Epidemio/2010; published online April 20. 